\title{
Research on the Relationships Among Learning Motivation, Learning Engagement, and Learning Effectiveness
}

\author{
Chih Huang*, Ying Yang \\ College of Economics and Management, Zhaoqing University, Zhaoqing City, Guangdong, China.
}

\begin{abstract}
How to cite this paper: Chih Huang, Ying Yang. (2021). Research on the Relationships Among Learning Motivation, Learning Engagement, and Learning Effectiveness. The Educational Review, USA, 5(6), 182-190.

DOI: $10.26855 /$ er.2021.06.004
\end{abstract}

Received: May 25, 2021

Accepted: June 20, 2021

Published: June 30, 2021

Corresponding author: Chih Huang, College of Economics and Management, Zhaoqing University, Zhaoqing City, Guangdong, China.

Email: 2753426367@qq.com

\begin{abstract}
This research mainly aims to explore the relationship between learning motivation and learning effectiveness and verify the mediating role of learning engagement in the relationship between learning motivation and learning effectiveness. Taking the undergraduates of Z University in China as the research object, this paper carried out an investigation through quantitative research, whose result reveals that the learning motivation (learning interest, self-development, professional needs, external expectations) has a significant positive effect on the learning effectiveness (learning level, response level, behavior level). In addition, to further verify the mediating effect of learning engagement in the relationship between learning motivation and learning effectiveness, this research adopted the bias-corrected bootstrap method to test the total effect, indirect effect, and direct effect respectively. The finding shows that learning engagement plays a partial mediating role in the relationship between learning motivation (intrinsic motivation, extrinsic motivation) and learning effectiveness (reaction level, learning level, and behavior level).
\end{abstract}

\section{Keywords}

Learning Motivation, Learning Effectiveness, Self-Efficacy

\section{Introduction}

Motivation is one of the determinant factors that affect learning. Hakan and Munire (2014) pointed out that learning motivation has an important effect on learners' learning attitudes and learning behaviors. For example, students with stronger learning motivation tend to have higher intention of learning, participate in class interaction more actively, and achieve more happiness and satisfaction from learning activities, while students who lack learning motivation are more likely to have less interest in learning activities, and feel painful and depressed in the process of learning. Several researchers consider that learning motivation is a crucial factor for students' academic achievement (e.g., Boaler, 1999; Zimmerman et al., 1992), in other words, the intensity of learning motivation plays an important role in stimulating or inhibiting students' effort and perseverance, as well as the corresponding learning behavior and learning outcomes. Secondly, given that there are differences in individuals' learning objectives as well as in the interest reward preferences, intrinsic or extrinsic motivational demands are likely to arise.

In addition, learning engagement refers to students' positive emotions that may continuously arise in the learning process, which is mainly manifested in students' strong interest in learning, their persistent attitudes faced with difficulties in learning, as well as their attitudes or behaviors of being fully engaged in learning, and fully concentrated free from the influence of external things. Harper and Quaye (2009) revealed a positive relationship between learning en- 
gagement and academic achievement, which implies the more actively the students participate in educational activities, the higher the graduation rate and the better performance in learning effectiveness.

On the basis of the discussions mentioned above, if college students can enhance their learning motivation and reinforce their learning engagement, it will be of great significance for the progress and development of students' learning effectiveness, and it is also an important process of expanding their learning ability. Therefore, the research will focus on learning motivation to explore its relationship with learning effectiveness and takes learning engagement as an intermediary factor to grasp the influence path of the development process from learning motivation to learning effectiveness more accurately.

\section{Theoretical Background and Hypothesis Development}

\subsection{Learning motivation}

Luthans and Sommers (2005) suggested that motivation is actually a psychological process that stimulates and guides human behavior, while goal theory proposes that motivation is a process in which goal-oriented activities are stimulated and sustained (Schunk et al., 2008). Therefore, motivation is the process of an individual's selection of direction, vigor, and persistence of behavior (Murphy \& Alexander, 2000), which integrates desire and effort to achieve goals. To sum up, the learning motivation in this research is defined as "a kind of motivation that can stimulate students to learn and maintain their interest in learning activities and guide students to achieve their learning objectives in a targeted manner”.

According to the extant studies on motivation, intrinsic motivation and extrinsic motivation are not only two major types of motivation widely discussed by scholars in the field of organizational behavior (Ryan \& Deci, 2000), but also the key factors that affect learners' academic achievements at various stages of education $(\mathrm{Ng} \& \mathrm{Ng}$, 2015). LaBelle (2005) pointed out the differences in individuals' rewards preferences and perceptions of learning, some students prefer intrinsic rewards while others prefer extrinsic rewards. The intrinsic reward of learning refers to the pleasure and satisfaction that students can gain in their academic learning activities, including demands for learning, interest in learning, ideals, self-esteem, self-actualization, etc. In addition, it focuses on inner desires and the goals are set and selected by individuals themselves, therefore, intrinsic reward is a self-oriented motivation. In terms of the extrinsic reward of learning, it focuses more on goal-driven inducements, in other words, students' pursuit of academic achievement aims to follow and achieve the goals, expectations, and compliments of important others such as society, family, and teachers or is related to their goals of winning honorary titles and scholarships as well as seeking admirable careers or social relationships, etc. Therefore, the extrinsic reward is another-directedness motivation. In short, the distinction between the above-mentioned two types of motivation mainly lies in that their different goals of stimulating individuals' action (Deci \& Ryan, 1985).

\subsection{Learning engagement}

Kuh (2003) pointed out that learning engagement refers to students' feelings, behavior, and thinking amid the learning process. Newmann et al. (1992) defined learning engagement as a kind of psychological investment and effort made by students aiming to enrich their knowledge and enhance their skills and striving to make more academic achievements in the understanding or mastery of their studies. In other words, learning engagement is a kind of optimistic, enterprising, proactive attitude towards learning in the face of academic tasks.

Fredricks et al. (2004) indicated that previous studies mostly focus on the test of a single engagement type and its influence on the result of a single interest, making it impossible to fully understand which type of engagement has the greatest influence on behavioral outcomes. Although there are different concepts or measurements of learning engagement put forward in subsequent research conducted by different scholars, they all have multidimensional constructs in nature. For example, Miserandino (1996) divides learning engagement into actions and emotions. Meyer and Turner (2002) believe that learning engagement consists of behavior engagement and emotional engagement. Fredricks et al. (2004) think that learning engagement should include behavioral engagement, emotional engagement, and cognitive engagement. According to Reeve (2012), learning engagement not only refers to learners' passive response to learning activities but also includes the process of independent initiating. Therefore, in addition to behavioral, emotional, and cognitive engagement, it is also necessary to add agentic engagement. The current studies generally agree that learning engagement is comprised of behavioral engagement, emotional engagement, and cognitive engagement. Behavioral engagement focuses more on students' enthusiasm for participation in various academic learning activities, social learning activities, and extracurricular learning activities held inside and outside the school. Emotional engagement attaches more importance to students' impressions of the learning environment and schoolwork as well as their positive 
and negative attitudes toward their teachers, classmates, and other members. Cognitive engagement consists of students' required proficiency in achieving academic achievements, their pursuit of learning effectiveness, as well as their application of learning strategies. As the three levels are interrelated to each other, it is not easy to distinguish them clearly. According to Fredricks et al. (2004), these factors are dynamically related within the individual, rather than isolated. In short, learning engagement is the overall performance in the aspects of individual behavior, emotion, and cognition.

\subsection{Learning effectiveness}

Learning effectiveness is an indicator to measure learners' learning outcomes, aiming to grasp students' understanding and mastery of disciplinary knowledge or skills as well as their changes after they have participated in the learning activities for a period of time. In terms of learning effectiveness, the school can collect relatively complete quantitative or qualitative data by virtue of such methods as tests, scales, interviews, observations, etc., so as to evaluate and judge whether students' learning outcomes have achieved the curriculum objectives from an integrated point of view. In addition, learning effectiveness can also be measured by learners' self-cognition of their own knowledge or skills. This research mainly focuses on how individuals evaluate their own learning performance, that is, students' self-cognition of their mastery of disciplinary knowledge and comprehensive abilities as well as their changes after a period of study in a professional course. Young et al. (2003) assume that learning performance can be defined as students' self-evaluation of the comprehensive knowledge, skills, and capability development they have gained, and the greater effort they have made into a particular course relative to other courses.

In terms of the measurement of learning outcomes, the learning effectiveness in previous studies mainly follows the four-level concept put forward by Kirkpatrick (1994), including (1) reaction: the degree to which learners like the course or their satisfaction with the course; (2) learning: the degree to which learners enhance their understanding or absorption of the knowledge, skills or any information they have acquired in the learning process; (3) behavior: the degree to which students improve their application of the knowledge and skills they have mastered into their work behavior after the course training; (4) result: the degree to which the change in students' behaviors contribute to aspecific organizational goal a group goal after the completion of the learning course.

Among the four levels, "result" is the most difficult to evaluate, and the reason is that as time goes by, students' learning results are likely to be influenced or interfered with by quite a few factors, making it difficult to merely attribute it to learning. As a consequence, this research will evaluate students' learning effectiveness from the three perspectives of students' reaction, learning, and behavior. From the perspective of reaction, it refers to the degree of conformity between the actual difficulty of the course contents as well as the teaching materials in use and individual learning expectations. From the perspective of learning, it refers to the degree of learners' self-cognition of the enhancement of their professional knowledge and skills, the better understanding of their work contents in the professional field, as well as the improvement of their creative thinking and analytical ability. As for behavior, it refers to the degree of learners' satisfaction with their own performance, their exertion and application of professional knowledge and skills, as well as their opinions on the help to further study or work.

\subsection{The relationship between learning motivation and learning engagement}

The self-determination theory (SDT) reveals that although the interests and goals to arouse the individual actions are different, individuals may also feel a sense of pleasure no matter they participate in a particular activity out of intrinsic motivations or extrinsic motivations (Knudson-Martin, 2011). In terms of intrinsic motivation, the reason why people actively participate in a specific task or activity mainly lies in that they can acquire internal pleasure and a sense of achievement from this process; As for extrinsic motivation, people may not be interested in the participation of a particular activity; however, they think that they can boost the realization of their personal goals after completing the task. Under such circumstances, they choose to actively participate in activities that are conducive to the achievement of their goals. As can be seen, their sense of pleasure is closely related to external and separable outcomes (Ryan \& Deci, 2000) such as money, compliment, and favorable social relationship.

As mentioned above, this research expects a positive relationship between learning motivation and learning engagement. When students are fully aware that they can acquire intrinsic or extrinsic learning interests and goals from the learning process, they will maintain a positive, enthusiastic, concentrated and persistent attitude toward learning, and adjust their learning strategies while encountering difficulties or failures to accomplish learning tasks. On the contrary, students with lower learning motivation will hold a negative attitude toward learning with lower participation in learning. According to Vollmeyer and Rheinberg (2000), students' learning motivation will affect their continuity of learning, and consequently, students with higher learning motivation spend more time on learning activities with stronger learning perseverance than those with lower learning motivation. On this basis, the following hypotheses to be tested are 
proposed in this research:

H1: Learning motivation has a significant positive effect on learning engagement

H1-1: Intrinsic learning motivation has a significant positive effect on learning engagement

H1-2: Extrinsic learning motivation has a significant positive effect on learning engagement

\subsection{Learning motivation and learning effectiveness}

Knudson-Martin (2011) suggested that individuals' goals and interests are the important factors that cause motivation. However, according to the model of the self-determination theory, the extrinsic motivation factor (goal) and the intrinsic motivation factor (interest) are a continuum (Deci \& Ryan, 2002), besides, this model also points out that seen from extrinsic motivation, although some students may not be interested in certain subjects or learning activities, they will also choose to participate in the classroom learning activities and strive to achieve their goals when they are fully aware that the accomplishment of learning activities is conducive to the realization of the expectations, and compliment from important others, gaining honors, and establishing favorable interpersonal relationships. Secondly, in terms of intrinsic motivation, when students with a strong interest in the learning set and choose the learning goals by themselves, they can obtain happiness and satisfaction from learning (Csikszentmihalyi, 1990), which will promote their learning effectiveness. Wolters (1999) indicated that students with stronger achievement motivation are more persistent in learning and can achieve higher learning effectiveness than those with lower achievement motivation. Accordingly, the research proposes the following hypotheses:

H2: Intrinsic motivation has a significant positive effect on learning effectiveness.

H2-1: Intrinsic motivation has a significant positive effect on the reaction level of learning effectiveness.

H2-2: Intrinsic motivation has a significant positive effect on the learning level of learning effectiveness.

H2-3: Intrinsic motivation has a significant positive effect on the behavior level of learning effectiveness.

H3: Extrinsic motivation has a significant positive effect on learning effectiveness.

H3-1: Extrinsic motivation has a significant positive effect on the reaction level of learning effectiveness.

H3-2: Extrinsic motivation has a significant positive effect on the learning level of learning effectiveness.

H3-3: Extrinsic motivation has a significant positive effect on the behavior level of learning effectiveness.

\subsection{Learning engagement and learning effectiveness}

Learning engagement reflects that students maintain a continuous positive attitude toward learning and have strong enthusiasm for learning as well as persistence in overcoming difficulties. In addition, they are fully concentrated on learning and are not susceptible to external disturbances. Therefore, learning engagement refers to students' psychological and behavioral concentration and efforts to learn to achieve learning objectives. Although they may encounter challenges and difficulties in the learning process, they still maintain a positive, active and persistent attitude toward learning, are willing to make more efforts into learning activities or tasks and feel delighted after the realization of the goal.

According to this research, learning engagement refers to students' investment into academic study, in an attempt to acquire new knowledge or skills through various academic tasks. In other words, individuals achieve good learning outcomes by means of continuously enhancing their learning capacity. Many studies have shown that students' learning engagement is positively related to their learning effectiveness (Prince, 2004). For example, Connell et al. (1994) demonstrated that students' emotional engagement has a positive effect on learning effectiveness. The research results of Greene et al. show that high school students' cognitive engagement has a direct effect on learning effectiveness. Carini et al. (2006) also manifested that students' engagement is correlated with the enhancement of learning level. The research results of Lam et al. (2012) also show a positive relationship between learning engagement and learning effectiveness, which can be used to predict students' academic performance and behaviors in the short term. On this basis, the following hypotheses are proposed in this research:

H4: Learning engagement has a significant positive effect on learning effectiveness.

H4-1: Learning engagement has a significant positive effect on the reaction level of learning effectiveness.

H4-2: Learning engagement has a significant positive effect on the learning level of learning effectiveness.

H4-3: Learning engagement has a significant positive effect on the behavior level of learning effectiveness.

\subsection{The mediating role of learning engagement in the relationship between learning motivation and learning effectiveness}

Motivation is an internal force that stimulates people to take action or advance towards goals. According to the self-determination theory, when individuals are aware that they can acquire interesting, pleasant, and satisfying interests 
from the heart in the learning process, or while they can achieve external goals such as living up to the expectations from important others, receiving compliments, and winning scholarships in academic activities, they will be stimulated to have an active, dedicated and concentrated attitude or behavior towards their participation in learning activities as long as the interests and goals are of great significance for individuals.

This research considers whether a student with learning motivation can perceive the improvement of his/her professional knowledge, skills, and non-professional ability, and achieve his learning interests and goals still depends on the process of learning engagement. Skinner et al. (2008) indicated that engagement is an indispensable element in the structure of motivation, besides learning engagement and learning motivation are interrelated and influence each other. However, the intensity of learning motivation will influence the degree of learning engagement. As a consequence, learning motivation is a prerequisite for learning engagement. Previous studies have also shown that students' learning engagement is a powerful indicator to predict students' academic performance and behavior (e.g., Connell et al., 1994; Finn \& Rock, 1997). In other words, students with higher learning achievement motivation are more willing to actively participate in learning activities and have a more active and persistent attitude toward the learning challenges and obstacles, which is likely to cause them to gain better learning outcomes in professional knowledge and skills as well as non-professional skills. Accordingly, this research proposes the following hypotheses:

H5: Learning engagement has a mediating effect on the relationship between intrinsic learning motivation and learning effectiveness.

H5-1: Learning engagement has a mediating effect on the relationship between intrinsic motivation and the reaction level of learning effectiveness.

H5-2: Learning engagement has a mediating effect on the relationship between intrinsic motivation and the learning level of learning effectiveness.

H5-3: Learning engagement has a mediating effect on the relationship between intrinsic motivation and the behavior level of learning effectiveness.

H6: Learning engagement has a mediating effect on the relationship between extrinsic learning motivation and learning effectiveness.

H6-1: Learning engagement has a mediating effect on the relationship between extrinsic motivation and the reaction level of learning effectiveness.

H6-2: Learning engagement has a mediating effect on the relationship between extrinsic motivation and the learning level of learning effectiveness.

H6-3: Learning engagement has a mediating effect on the relationship between extrinsic motivation and the behavior level of learning effectiveness.

\section{Research Methods}

\subsection{Sample and procedures}

The data were collected from undergraduates of College of Economic and Management of University Z in China, which of 224 questionnaires distributed, among which 15 were invalid and 209 were valid, representing a 93.3\% response rate. Amongall the respondents, female students accounted for $63.6 \%$ of the respondents; students from rural areas accounted for $53.3 \%$; freshmen and juniors accounted for $43.5 \%$ and $28.7 \%$ respectively. In terms of professional departments, students majoring in science and engineering accounted for $42.6 \%$, and students majoring in liberal arts accounted for $34.4 \%$.

\subsection{Common method variance Analysis}

Considering that the respondents of all the questionnaires in this study were all students, it is prone to the occurrence of common method variance (CMV) due to the single source of respondents. Therefore, Haman's single-factor post hoc analysis (Podsakfoff et al., 2003) was further conducted to detect whether CMV is likely to happen. All the items from every construct were entered into principal component factor analysis, and checked the unrotated factor solution, and examined to assess the number of factors that could cause the variance in the variables (Tehseen et al., 2017). The analysis result shows that twelve factors were extracted through unrotated principal component factor analysis and the explained variance of the first factor accounts for $37.86 \%(<50 \%)$, this means that CMV is not a serious problem in the study (Mattila \& Enz, 2002).

\subsection{Measures}

To confirm the rationality of the components of latent variables, this research will further test the fitness of the model by virtue of confirmatory factor analysis (CFA). In the meantime, this research will make a second-order confirmatory 
factor analysis of partial construct to solve the problem of the high correlation between common factors in multi-factor confirmatory factor analysis. By extracting higher-order common factors, it will not only be more in line with the concept of construct measurement in this research but also make the model well expressed and more concise.

Learning Motivation was measured using Liao's (2004)11-item scale, which consists of two sub-facets, including (1) interest in knowledge: (e.g., I like to learn because I am interested in the course content and activities), 5 questions; (2) self-development: (e.g., I like to learn because it can enable me to be a more learned person), 6 questions. The second-order CFA showed that the components have an adequate fit to the question data $(\chi 2=40.69, \chi 2 / \mathrm{df}=2.14$, CFI $=$ $0.967, \mathrm{GFI}=0.953, \mathrm{NNFI}=0.968, \mathrm{RMSEA}=0.074), \alpha=0.875$

In addition, two sub-facets of extrinsic motivation, which consist of a total of 11 items, including (1) career development (e.g., I like to learn because it can enable me to meet my future career and work needs), 5 items; (2) external expectations (e.g., I like to learn because it can encourage my family and support me), 6 items. Second-order CFA showed an adequate fit to the data $(\chi 2=77.91, \chi 2 / d f=2.99, \mathrm{CFI}=0.944, \mathrm{GFI}=0.924, \mathrm{NNFI}=0.922, \mathrm{RMSEA}=0.09), \alpha=0.863$.

Learning Engagement was measured using the scale developed by Fredricks and McColskey (2012) and revised by Li (2018). Three sub-facets consist of a total of 16 items: (1) behavioral engagement (e.g., I will actively speak up to express my own views), 5 items $(\alpha=0.86)$; (2) emotional engagement (e.g., I have strong enthusiasm for learning), 6 items $(\alpha=0.89)$; (3) cognitive engagement (e.g., I have my own study plan), 5 items $(\alpha=0.88)$. Considering that learning engagement is the overall performance of individual behavior, emotion and cognition, the second-order CFA is carried out, whose results showed an adequate fit to the data $(\chi 2=197.67, \chi 2 / d f=2.27, \mathrm{CFI}=0.930$, GFI $=0.897$, NNFI $=0.916$, RMSEA $=0.078), \alpha=0.921$.

Learning Effectiveness was assessed using the scale compiled by Chang (2018) which integrated and revised the scales developed by quite a few scholars. Three sub-facets are composed of a total of 16 items, including (1) reaction level (e.g., the course content is in line with the expectations), a total of 4 items $(\alpha=0.859)$; (2) learning level (e.g., learning can enrich my professional knowledge), a total of 6items $(\alpha=0.862)$, (3) behavior level (e.g., I feel satisfied with my performance after learning), a total of six items $(\alpha=0.869)$.

\section{Results}

In this study, Structural Equation Modeling (SEM) is used to verify the research hypotheses with a two-step approach (Hair et al., 2011). The first phase is about the analysis of the measurement model. The second phase is about the verification of the structural model.

\subsection{The measurement model}

In this study, CFA is used to measure the validity and reliability of all constructed items. First of all, as shown in Table 1: (1) Cronbach's $\alpha$ values all exceed 0.7, indicating that there is good internal consistency among the items of each dimension (Nunnally \&Bernstein, 1994). (2) The construction reliability (CR) is between 0.839 and $0.921(>0.6)$. (3) In terms of the measurement of convergent validity, the average variance extracted (AVE) of each latent construct is greater than 0.5 (Fornell \& Larcker, 1981). (4) In terms of the measurement of discriminant validity, the AVE for each latent construct exceeds the respective squared correlation (Fornell \& Larcker, 1981). The data above-mentioned all exceed the recommended value, indicating that the measurement model in this study has good reliability, discriminant validity, and convergent validity.

Table 1. Descriptive statistics, reliability, and validity of this research constructs

\begin{tabular}{lcccccccc}
\hline & Cronbach's $\alpha$ & C.R. & AVE & 1. & 2. & 3. & 4. & 5. \\
\hline 1. IM & 0.875 & 0.839 & 0.722 & $\mathbf{0 . 8 5 0}$ & & & & \\
2.EM & 0.863 & 0.793 & 0.658 & $0.622^{* *}$ & $\mathbf{0 . 8 1 1}$ & & & \\
3. LE & 0.921 & 0.921 & 0.795 & $0.622^{* *}$ & $0.445^{* *}$ & $\mathbf{0 . 8 9 2}$ & & \\
4. RA & 0.859 & 0.875 & 0.639 & $0.445^{* *}$ & $0.343^{* *}$ & $0.615^{* *}$ & $\mathbf{0 . 7 9 9}$ & \\
5. LA & 0.862 & 0.870 & 0.576 & $0.557^{* *}$ & $0.480^{* *}$ & $0.632^{* *}$ & $0.577^{* *}$ & $\mathbf{0 . 7 5 9}$ \\
6. BA & 0.869 & 0.870 & 0.527 & $0.622^{* *}$ & $0.538^{* *}$ & $0.665^{* *}$ & $0.600^{* *}$ & $0.764^{* *}$ \\
\hline
\end{tabular}

Notes: $\mathrm{IM}=$ intrinsic motivation; $\mathrm{EM}=$ extrinsic motivation; $\mathrm{LE}=$ learning engagement; $\mathrm{RA}=$ reaction aspect; $\mathrm{LA}=$ learning aspect; $\mathrm{BA}=$ behavior aspect; C.R.= construct reliability; AVE= average variance extracted; The square root of AVE is displayed in bold on the diagonal of the matrix. 


\subsection{Structural model}

First of all, as shown in Figure 1, the structural model has an adequate fit to the data $\left(\chi^{2}=524.53, \chi^{2} / \mathrm{df}=2.65\right.$, CFI= 0.915 , GFI $=0.864$, NNFI $=0.901$, RMSEA $=0.076$ ), in the meantime, the path analysis of the structural model is carried out to verify the hypothesis proposed in this research. As shown in Figure 1, intrinsic motivation and extrinsic motivation have significant positive effects on learning engagement respectively $(\beta=0.64, t=8.66 ; \beta=0.42, t=5.77)$, therefore, H1-1 and H1-2 are supported. Secondly, the intrinsic motivation and extrinsic motivation have significant positive effects on the reaction level $(\beta=0.51, \mathrm{t}=5.42 ; \beta=0.23, \mathrm{t}=3.14)$, the learning level $(\beta=0.35, \mathrm{t}=4.14 ; \beta=0.38, \mathrm{t}=5.04)$ and behavior level $(\beta=0.28, t=3.30 ; \beta=0.51, t=5.84)$ respectively, therefore, $\mathrm{H} 2-1 \sim \mathrm{H} 2-3$, H3-1 H3-3 are supported. In addition, learning engagement has a significant positive effect on the reaction level $(\beta=0.32, t=3.16)$, learning level $(\beta$ $=0.40, \mathrm{t}=4.08)$ and behavior level $(\beta=0.39, \mathrm{t}=3.90)$ respectively, therefore, $\mathrm{H} 4-1 \sim \mathrm{H} 4-3$ are also supported.

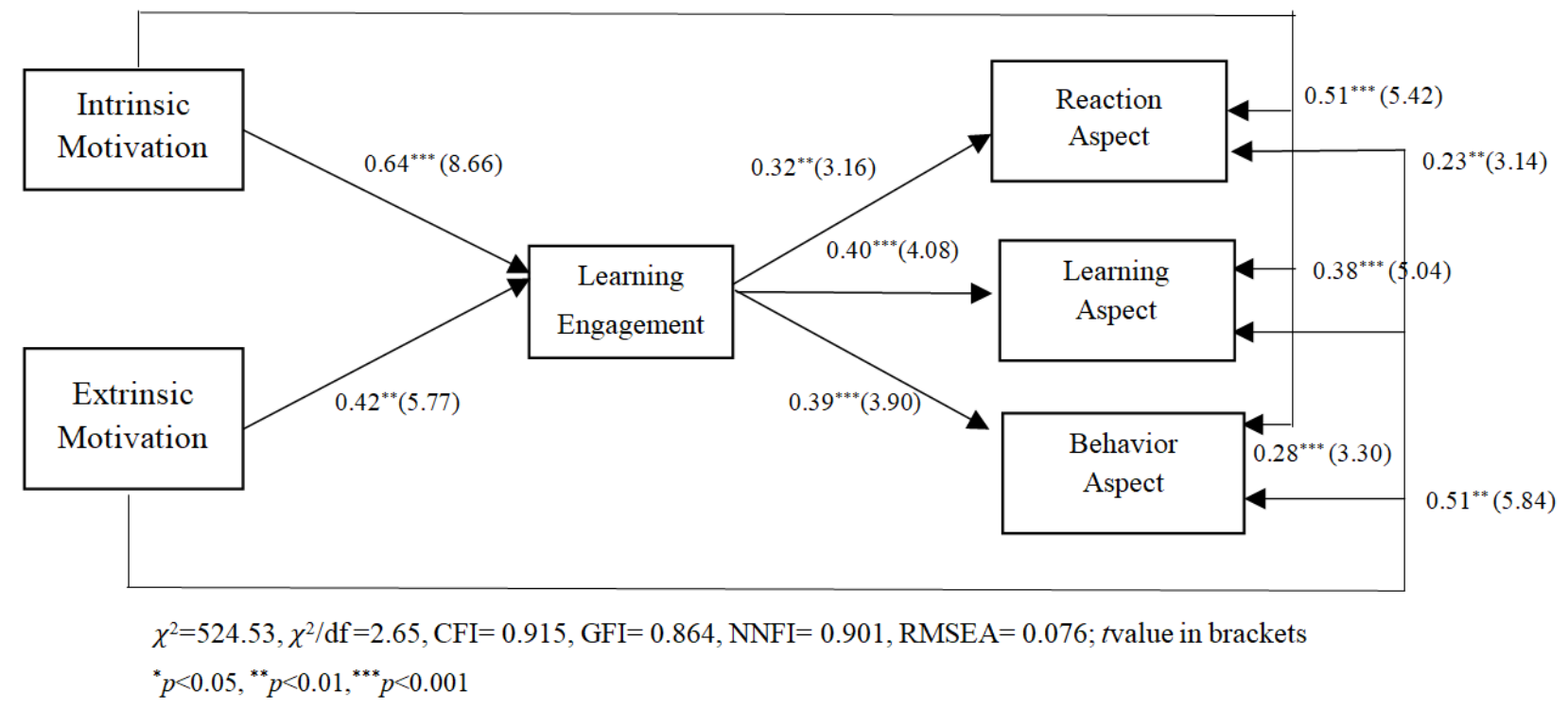

Figure 1. Hypothesized model with path coefficients.

In addition, to verify the mediating role of learning engagement in the relationship between learning motivation and learning effectiveness, the Bias-Corrected Bootstrap method and the 95\% confidence interval (CI) are adopted to test the total effect, indirect effect, and direct effect respectively. Moreover, whether the interval between the lower bounds and the upper bounds of the confidence limit includes zero value is taken as the criterion to judge the intermediate effect. As shown in Table 2, in terms of the test of the total effect, the limit value of the confidence interval of all influencing paths does not include zero. Secondly, the limit value of the confidence interval of the indirect effect of each path does not include zero. In terms of direct effect, the limit value of the confidence interval does not include zero as well. On the basis of this data, learning engagement plays a partial mediating role in the relationship between learning motivation (intrinsic motivation, extrinsic motivation) and learning effectiveness (reaction level, learning level, and behavior level). Thus, H5-1 H5-3, H6-1 H6-3 are supported.

Table 2. The path analysis of the mediating effect of LE

\begin{tabular}{ccccccc}
\hline \multirow{2}{*}{ Effects } & \multicolumn{2}{c}{ Total effect } & \multicolumn{2}{c}{ Indirect effect } & \multicolumn{2}{c}{ Direct effect } \\
Path & Lower bounds & Upper bounds & Lower bounds & Upper bounds & Lower bounds & Upper bounds \\
\hline IM $\rightarrow$ LE $\rightarrow$ RA & 0.514 & 0.833 & 0.023 & 0.507 & 0.240 & 0.939 \\
IM $\rightarrow$ LE $\rightarrow$ LA & 0.457 & 0.741 & 0.051 & 0.503 & 0.190 & 0.816 \\
IM $\rightarrow$ LE $\rightarrow$ BA & 0.406 & 0.648 & 0.077 & 0.406 & 0.079 & 0.495 \\
EM $\rightarrow$ LE $\rightarrow$ RA & 0.202 & 0.520 & 0.063 & 0.408 & 0.540 & 0.544 \\
EM $\rightarrow$ LE $\rightarrow$ LA & 0.400 & 0.704 & 0.560 & 0.408 & 0.271 & 0.795 \\
EM $\rightarrow$ LE $\rightarrow$ BA & 0.545 & 0.789 & 0.110 & 0.279 & 0.313 & 0.711 \\
\hline
\end{tabular}

Notes: IM= intrinsic motivation; $\mathrm{EM}=$ extrinsic motivation; $\mathrm{LE}=$ learning engagement; $\mathrm{RA}=$ reaction aspect; $\mathrm{LA}=$ learning aspect; $\mathrm{BA}=$ behavior aspect. 


\section{Conclusion}

This research mainly aims to explore the relationship between learning motivation and learning effectiveness and to verify the mediating role of learning engagement in learning motivation and learning effectiveness. As can be seen from the research results, students' learning motivation has a significant positive effect on the learning effectiveness, whether the learning motivation is out of their expectations of getting pleasure and satisfaction from learning, or out of their goal to live up to social expectations and receive compliments from important others, which is in line with the concept of self-determination theory. Secondly, students with higher intrinsic and extrinsic motivation will have an optimistic, enterprising, and active learning attitude toward various academic tasks, which will, in turn, enable students to better absorb the learning content, perceive the work content in the professional field, and feel satisfied with their own performance in exerting and applying their professional knowledge and skills. Therefore, it is necessary for schools to host learning exchange meetings to discover the problems that students face in the learning process, to help students enhance their learning motivation, promote their enthusiasm for learning, and realize and discover their own value from learning. It is feasible for teachers to discuss learning methods and learning strategies with students to stimulate students' learning motivation and interest and help them set their own learning goals, which will have a positive effect on their learning mood and learning engagement intention and will contribute to enhancing their learning effectiveness.

\section{Research Limitations and Future Research Directions}

The results of this research at least have the following limitations. Firstly, the research object of this research is limited to the students of the College of Economics and Management of Z University, making the research results merely applicable to the university. Therefore, there are great limitations in terms of external validity. Secondly, in the process of data collection, some students may have a negative and defensive attitude toward answering certain questions. Therefore, students may fill in the questionnaires at will, which is likely to cause biases in the analysis of the research results.

Finally, it is practicable to add other contextual variables into subsequent research, such as teachers' teaching strategies and classroom learning atmosphere to make the inference and analysis of the influence relationship between variables at different levels more accurate through cross-level research design. Secondly, it is also feasible to make a comparative analysis of the students from other universities majoring in the same major, which not only can establish the validity of such research but also can have a better understanding of the problems and differences.

\section{References}

Boaler, J. (1999). Participation, knowledge, and beliefs: A community perspective on mathematics learning. Educational Studies in Mathematics, 40, 259-281.

Carini, R. M., Kuh, J. D., and Klein, S. P. (2006). Student engagement and student learning: Testing the linkages. Research in Higher Education, 47, 1-32.

Chang, L. H. (2018). A study on learning attitude, learning performance, and learning satisfaction for the students of the cooperative technique education program in junior high schools. unpublished master's thesis, National Kaohsiung University of Science and Technology

Connell, J. P., Spencer, M. B., and Aber, J. L. (1994). Educational risk and resilience in African-American youth: Context, self, action, and outcomes in school. Child Development, 65, 493-506.

Csikszentmihalyi, M. (1990). Flow: The psychology of optimal experience. New York: Harper Collins.

Deci, E. L. and Ryan, R. M. (1985). Intrinsic motivation and self-determination in human behavior. New York: Plenum Publishing Co.

Deci, E. L. and Ryan, R. M. (2002). Handbook of self-determination research. Rochester, NY: University of Rochester Press.

Finn, J. D. and Rock, D. A. (1997). Academic success among students at risk for school failure. Journal of Applied Psychology, 82: 221-234.

Fornell, C. and Larcker, D. F. (1981). Evaluating structural equation models with unobservable variables and measurement error. Journal of Marketing Research, 18, 39-50.

Fredricks, J. A. and McColskey, W. (2012). The measurement of student engagement: A comparative analysis of various methods and student self-report instruments. In S. L. Christenson, A. L. Reschly, \& C. Wylie (Eds.), Handbook of research on student engagement (pp. 763-782). Springer Science + Business Media.

Fredricks, J. A., Blumenfeld, P. C., and Paris, A. H. (2004). School engagement: Potential of the concept, state of the evidence. Re- 
view of Educational Research, 74, 59-109.

Hair, J. F., Anderson, R. E., Tatham, R. L., and Black, W. (2011). Multivariate data analysis. Technometrics, 31: $103-104$.

Hakan, K. and Munire, E. (2014). Academic motivation: gender, domain and grade differences. Social and Behavioral Sciences, 143: 708-715.

Harper, S. R. and Quaye, S. J. (2009). Student Engagement in Higher Education: Theoretical Perspectives and Practical Approaches for Diverse Populations. New York: Routledge.

Kirkpatrick, D. L. (1994). Evaluating training programs: The four levels. San Francisco, CA: Berrett-Koehler Publishers.

Knudson-Martin, J. (2001). A Combined Model for Understanding Motivation. American International Journal of Contemporary Research, 1: 11-16.

Kuh, G. D. (2003). What we're learning about student engagement from NSSE: Benchmarks for effective educational practices. Change: The Magazine of Higher Learning, 35, 24-32.

La Belle, J. E. (2005). The paradox of safety hopes and rewards: are you rewarding the right behavior? Professional Safety, 50, 37-42.

Laio, J. S. (2004). A study on the relationship between learning motivation and learning satisfaction of postgraduate, unpublished master's thesis, National Pingtung University, Taiwan.

Lam, S. F., Wong, B. P. H., Yang, H., and Liu, Y. (2012). Understanding Student Engagement with a Contextual Model. In Christenson, S. L., Reschly, A. L. \& Wylie, C. (Eds.), Handbook of Research on Student Engagement (pp.403-419). NY: Springer.

Li Xiaofang. (2018). A study on academic engagement and its influencing factors of students of the department of tourism service and management in secondary vocational schools. Unpublished master's thesis, Liaoning Normal University.

Luthans, K. W. and Sommers, S. (2005). The impacts of high performance work on industry level outcomes. Journal of Managerial Issues, 17, 327-345.

Mattila, A. S. and Enz, C. A. (2002). The role of emotions in service encounters. Journal of Service Research, 4, $268-277$.

Miserandino, M. (1996). Children who do well in school: Individual differences in perceived competence and autonomy in above-average children. Journal of Educational Psychology, 88, 203-214.

Murphy, P. K. and Alexander, P. A. (2000). A motivated exploration of motivation terminology. Contemporary Educational Psychology, 25, 3-52.

Ng, C. F. and Ng, P. K. (2015). A review of intrinsic and extrinsic motivations of ESL Learners. International Journal of Languages, Literature and Linguistics, 1, 98-105.

Nunnally, J. C. and Bernstein, I. (1994). Psychometry Theory (3rd Ed.). New York: McGraw-Hill.

Podsakfoff, P. M., MacKenzie, S. B., Lee, J. Y., and Podsakfoff, N. P. (2003). Common method biases in behavioral research: A critical review of the literature and recommended remedies. Journal of Applied Psychology, 88: 879-903.

Prince, M. (2004). Does active learning work? A review of the research. Journal of Engineering Education, 93, $223-231$.

Reeve, J. (2012). A self-determination theory perspective on student engagement. In Christenson, S. L., Reschly, A. L. \& Wylie, C. (Eds.), Handbook of Research on student engagement (pp. 149-172). Springer Science + Business Media.

Ryan, R. M. and Deci, E. L. (2000). Intrinsic and extrinsic motivations: Classic definitions and new directions. Contemporary Educational Psychology, 25, 54-67.

Schunk, D. H., Pintrich, P. R., and Meece, J. L. (2008). Motivation in education: Theory, research, and applications (3rd ed.). Upper Saddle River, NJ: Pearson Prentice Hall.

Skinner, E., Furrer, C., Marchand, G., and Kindermann, T. (2008). Engagement and disaffection in the classroom: Part of a larger motivational dynamic? Journal of Educational Psychology, 100, 765-781.

Tehseen, S., Ramayah, T., and Sajilan, S. (2017). Testing and controlling for common method variance: A Review of available methods. Journal of Management Sciences, 4: 146-175.

Vollmeyer, R. and Rheinberg, F. (2000). Does motivation affect performance via persistence. Learning and Instruction, 10, $293-309$.

Wolters, C. A. (1999). The relation between high school student motivational regulation and their use of learning strategies, efforts, and classroom performance. Learning \& Individual Differences, 11, 281-301.

Young, M. R., Klemz, B. R., and Murphy, J. W. (2003). Enhancing learning outcomes: The effects of instructional technology, learning styles, instructional methods, and student behavior. Journal of Marketing Education, 25, 130-142.

Zimmerman, B. J., Bandura, A., and Martinez-Pons, M. (1992). Self-motivation for academic attainment: The role of self-efficacy beliefs and personal goal setting. American Educational Research Journal, 29, 663-676. 